\title{
The Effect of Hydrothermal Treatment on Silver Nanoparticles Stabilized by Chitosan and Its Possible Application to Produce Mesoporous Silver Powder
}

\author{
Dang Viet Quang and Nguyen Hoai Chau \\ Institute of Environmental Technology, Vietnam Academy of Science and Technology, 18 Hoang Quoc Viet, Cau Giay, Hanoi, Vietnam \\ Correspondence should be addressed to Dang Viet Quang; dvquanghh2001@yahoo.com
}

Received 29 June 2013; Accepted 28 September 2013

Academic Editor: Thierry Barriere

Copyright (C) 2013 D. Viet Quang and N. Hoai Chau. This is an open access article distributed under the Creative Commons Attribution License, which permits unrestricted use, distribution, and reproduction in any medium, provided the original work is properly cited.

\begin{abstract}
Aggregation state of silver nanoparticles dispersed in an aqueous solution greatly varies with storage and treatment conditions. In this study, silver nanoparticles synthesized in chitosan solution by a chemical reduction method were hydrothermally treated at different temperatures. The variation in the aggregation state of silver nanoparticles in the solution was observed by UV-Vis spectroscopy and field emission transmission electron microscopy. Results indicated that a phase transition occurred while silver nanoparticles were hydrothermally treated for $5 \mathrm{~h}$ at 100 and $120^{\circ} \mathrm{C}$; however, they aggregated and completely precipitated at $150^{\circ} \mathrm{C}$. Mesoporous silver powder obtained by hydrothermal treatment at $150^{\circ} \mathrm{C}$ was characterized by using X-ray diffraction technique, BET analyzer, and scanning electron spectroscope.
\end{abstract}

\section{Introduction}

Silver nanoparticles have become the most widely commercialized nanomaterials due to thier unique physicochemical and biological properties [1]. Silver nanoparticles can be synthesized and stabilized in the presence of polymers [2-7] in an aqueous solution or organic solvents. They can also be stabilized in the pores of porous materials where tiny spaces or channels act as spatial hindrance, which inhibits the growth of silver particles [8-11]. The size and shape of silver nanoparticles in porous materials depend on their pore diameters and are almost stable after synthesis, whereas that of silver nanoparticles in solutions is affected by various factors including storing conditions, the type and concentration of stabilizer, the concentration of silver nanoparticles, and synthetic routes. The properties, applicability and efficiency of final products are greatly related to the size, the shape, and the aggregation state of silver nanoparticles.

Silver powder has been widely used in catalysis, electronics, chemical industry, and biomedical application [12]. Electronic industry consumes large amounts of silver powder that is usually used as conductive paste [13-16]. Several studies have indicated that mesoporous silver powders with higher porosity and larger surface area engender higher application efficiencies such as reducing firing temperature of conductive film [17], enhancing the resistance of heat exchanger material at ultralow temperature [18], or increasing catalytic activity of an oxidation reaction $[19,20]$. Recently, due to the rapid development of electronic industry, it demands a huge amount of high quality silver powder. Thus, scientists have investigated and proposed different methods such as spray pyrolysis [21-23], sonochemical synthesis [24], $\gamma$-radiation [25], and chemical reduction [13, 14, 26-28] to prepare silver powder.

Hydrothermal technique has been realized as an excellent and cost-effective method for the processing of nanostructural materials $[29,30]$. It has been used to synthesize and control the growth and the phase transition of silver crystals [31-37]. However, the effect of hydrothermal treatment on presynthesized silver nanoparticles has been scarcely investigated. Therefore, the objective of this work is to investigate the stability of silver nanoparticles under the hydrothermal 


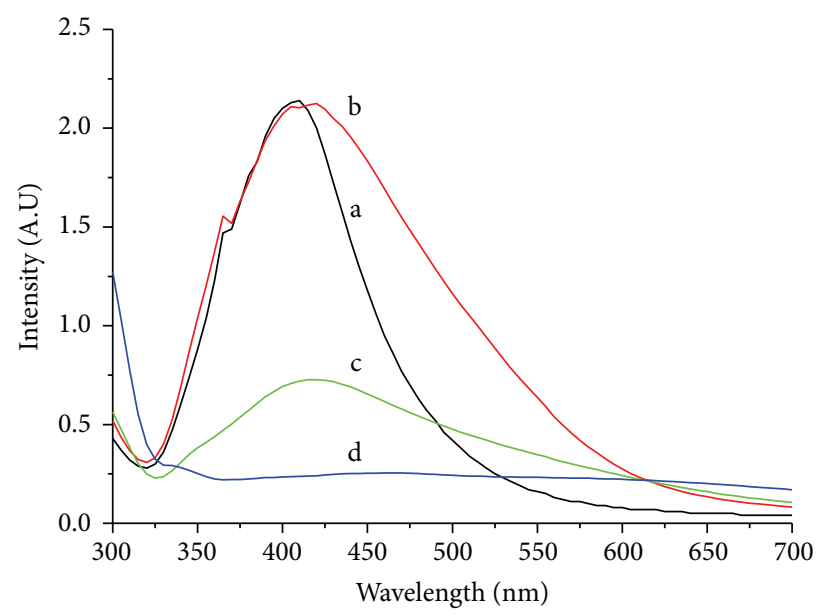

a: As-synthesized solution
b: Solution treated at $100^{\circ} \mathrm{C}$ for $5 \mathrm{~h}$
c: Solution treated at $120^{\circ} \mathrm{C}$ for $5 \mathrm{~h}$
d: Solution treated at $150^{\circ} \mathrm{C}$ for $5 \mathrm{~h}$

FIGURE 1: UV-Vis spectra of silver nanoparticle solution treated at various temperatures.

condition and to recover mesoporous silver powder from a silver nanoparticle/chitosan solution by hydrothermal treatment.

\section{Method}

2.1. Materials. Silver nitrate was purchased from DaeJung Chemical and Metals Co., Ltd. $\mathrm{NaBH}_{4}$ was obtained from Duksan Pharmaceutical Co., Ltd. Chitosan (low molecular weight) supplied by Sigma-Aldrich was used to prepare a stock solution (10 g/L) in $1 \%$ acetic acid, which will be utilized for further experiments.

2.2. Synthesis of Silver Nanoparticles. Silver nitrate $(787 \mathrm{mg})$ was weighed and transferred into $3 \mathrm{~L}$ beaker containing $880 \mathrm{~mL}$ of chitosan solution (500 ppm) and mixed for $1 \mathrm{~h}$ using a magnetic stirrer. Then, $120 \mathrm{~mL}$ of $\mathrm{NaBH}_{4}(0.05 \mathrm{M})$ was dropwise added at room temperature $\left(25^{\circ} \mathrm{C}\right)$ while the solution was vigorously stirred. The solution changed from transparent to yellow when $\mathrm{NaBH}_{4}$ added indicated the formation of silver nanoparticles.

2.3. Hydrothermal Treatment. To investigate the effect of hydrothermal treatment on silver nanoparticles, $200 \mathrm{~mL}$ of as-synthesized silver nanoparticles solution was taken into a $500 \mathrm{~mL}$ Teflon-lining stainless steel autoclave. After being tightened, it was heated at various temperatures for $5 \mathrm{~h}$ and slowly cooled down. The solution in autoclave was decanted and precipitated silver was collected and washed with deionized water and then filtered. The obtained precipitated silver was dried at $105^{\circ} \mathrm{C}$ for $2 \mathrm{~h}$ for further characterization.

2.4. Characterization. UV-Vis absorption spectra were acquired at room temperature using UV-Vis spectrophotometer Optizen $2120 \mathrm{UV}$ over the wavelength ranging from $300 \mathrm{~nm}$ to $700 \mathrm{~nm}$. The morphologies of samples were investigated using field emission scanning electron microscopy
(FE-SEM, Hitachi, S-4800) with an accelerating voltage of $15 \mathrm{kV}$. Field emission scanning transmission electron microscopy (FE-STEM) pictures were acquired using a JEOL 2000 FX instrument. X-ray diffraction (XRD) was carried on XRD-6000 (Shimazu) operating at $40 \mathrm{kV}, 100 \mathrm{~mA}$ with the $\mathrm{Cu} / \mathrm{K} \alpha$ radiation $(\gamma=1.54059 \AA)$. The Brunauer-EmmettTeller (BET) surface area and the porosity of the samples were studied by using a nitrogen adsorption instrument (Micrometrics ASAP 2020). All the samples measured were degassed at $105^{\circ} \mathrm{C}$ for $3 \mathrm{~h}$ before analyzing.

\section{Results and Discussion}

3.1. Morphology and Structure of Silver Nanoparticles. UVVis spectra of silver nanoparticle solution treated at different temperatures are shown in Figure 1. As seen in this figure, adsorption band at $415-425 \mathrm{~nm}$ was observed on the spectra of the as-synthesized solution and solution treated at 100 and $120^{\circ} \mathrm{C}$ for $5 \mathrm{~h}$. The observation of this adsorption band is attributed to the characteristic surface Plasmon resonance of silver nanoparticles, which indicated the presence on silver nanoparticles in the solution. In this study, the absorption band of as-synthesized sample is sharp and intensive, but its intensity and sharpness decreased after hydrothermal treatment at 100 and $120^{\circ} \mathrm{C}$. Moreover, the position of adsorption peak shifted toward longer wavelength. The reduction in its intensity may refer to the decrease in the concentration of silver nanoparticles. The red shift implies the increase in size and transition in the shape of silver nanoparticles. Shoulders around $370 \mathrm{~nm}$ and broad peaks at $420-425 \mathrm{~nm}$ observed on their spectra suggest the occurrence of anisotropic particles [31]. Those anisotropic particles may cause the structural transition during hydrothermal treatment, which results in the formation of silver particles with different shape. This observation can be further affirmed by TEM analysis shown in Figure 2. The intensity of the adsorption band was rapidly 


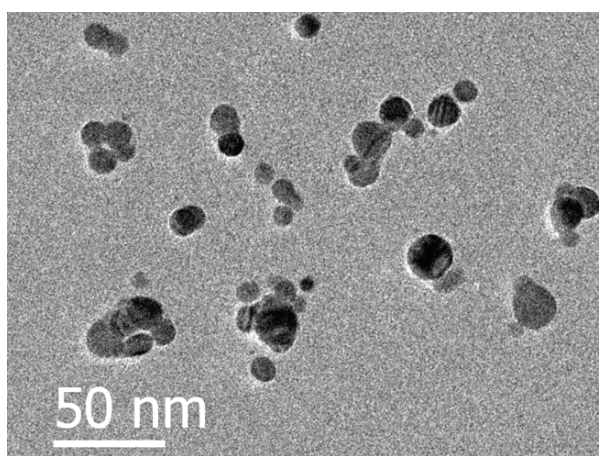

(a)

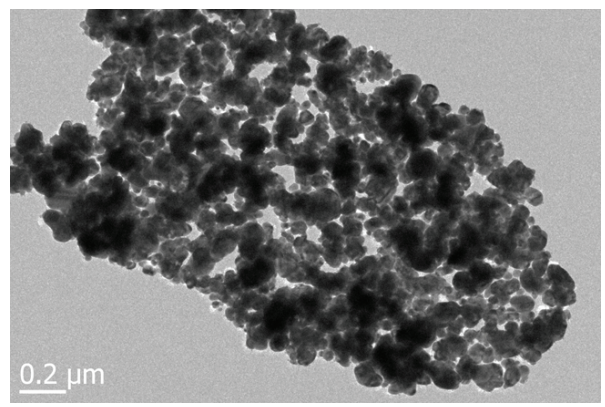

(c)

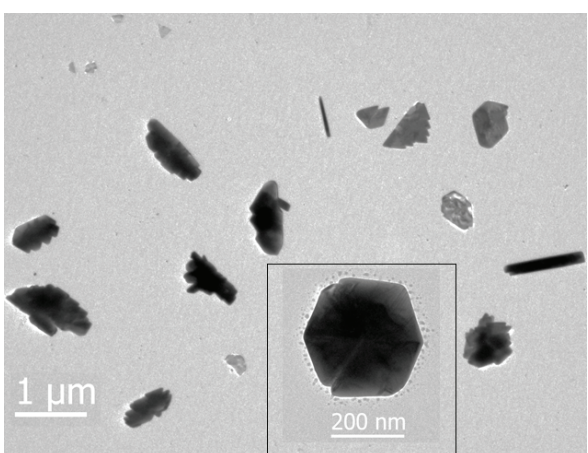

(b)

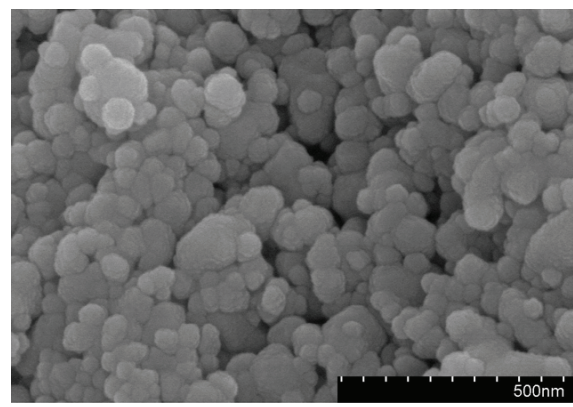

(d)

Figure 2: TEM images of as-synthesized silver nanoparticles (a) treated at $100^{\circ} \mathrm{C}(\mathrm{b})$ and $150^{\circ} \mathrm{C}(\mathrm{c})$ and an SEM image of silver powder (d).

decreased as temperature increased and it disappeared when sample treated at $150^{\circ} \mathrm{C}$ for $5 \mathrm{~h}$. The disappearance of the adsorption band refers to the attenuation of surface Plasmon resonance of silver nanoparticles. In other words, it indicated the absence of silver nanoparticles in the solution. In fact, brown precipitate was found at the bottom and on the wall of autoclave after treated at $150^{\circ} \mathrm{C}$. It is evident that silver nanoparticles in the solution were aggregated and precipitated.

As-synthesized silver nanoparticles have quasi-spherical shape with the size ranging from 5 to $20 \mathrm{~nm}$ (Figure 2(a)). After treatment at $100^{\circ} \mathrm{C}$, silver particles with various sizes and shapes were obtained (Figure 2(b)). The existence of rod and plate in this sample implies the anisotropic growth of silver nanoparticles. In this system, extremely small particles with higher surface energy tend to merge into larger ones to make them larger, while the small particles get smaller and disappear. This is well characterized in Figure 2(b) (inset), where a large particle is surrounded by numerous small ones, which would be likely to deposit on the surface of the larger particles. The stronger interaction of chitosan with a preferential facet of silver nanoparticles can be attributed to the anisotropic growth, resulting in the formation of different shapes such as nanoplate and nanorod [38]. However, as treated at $150^{\circ} \mathrm{C}$, we obtained aggregates by the random flocculation of silver nanoparticles (Figures 2(c) and 2(d)). In fact, the growth in the size of nanoparticle and their flocculation in solution are natural processes, which simultaneously occur to reduce surface energy of small particles. Depending on the thermodynamic condition, one process can be faster and dominant over another. In this work, it is likely that the rate of random flocculation dominated the growth rate of silver nanoparticles at $150^{\circ} \mathrm{C}$, which resulted in the aggregation and precipitation of silver clusters.

3.2. Mesoporous Silver Powder. Figure 3 presents the XRD pattern of silver powder obtained by hydrothermal treatment at $150^{\circ} \mathrm{C}$. The peaks at $37.84^{\circ}, 44.04^{\circ}, 64.23^{\circ}$, and $77.20^{\circ}$ are assigned to the diffraction of (111), (200), (220), and (311) planes of the face centered cubic phases of silver, respectively. The analysis of XRD indicated that the powder comprises pure metallic silver.

The porous properties of the silver powder were studied by nitrogen adsorption-desorption method. Sorption isotherm of silver powder shown in Figure 4 is corresponding to type IV of IUPAC classification of sorption isotherms [39]. The hysteresis loop implies the occurrence of pore condensation, indicating that silver powder is associated with a mesoporous structure. An indistinguishable inflection point at the initial part of the isotherm may refer to a slightly weak interaction between silver powder and nitrogen atoms. The specific surface area of the silver powder $\left(8.5 \mathrm{~m}^{2} / \mathrm{g}\right)$ was determined by the BET method. The Barret, Joyner, and Halenda (BJH) method was applied to the calculation of total pore volume and pore size distribution. Result indicates that the powder has the total pore volume of $0.12 \mathrm{~cm}^{3} / \mathrm{g}$. The pore size distribution of silver powder is displayed in Figure 4 (inset), indicating that the product is a mesoporous material with pore sizes mostly ranging from 7 to $30 \mathrm{~nm}$. This result 


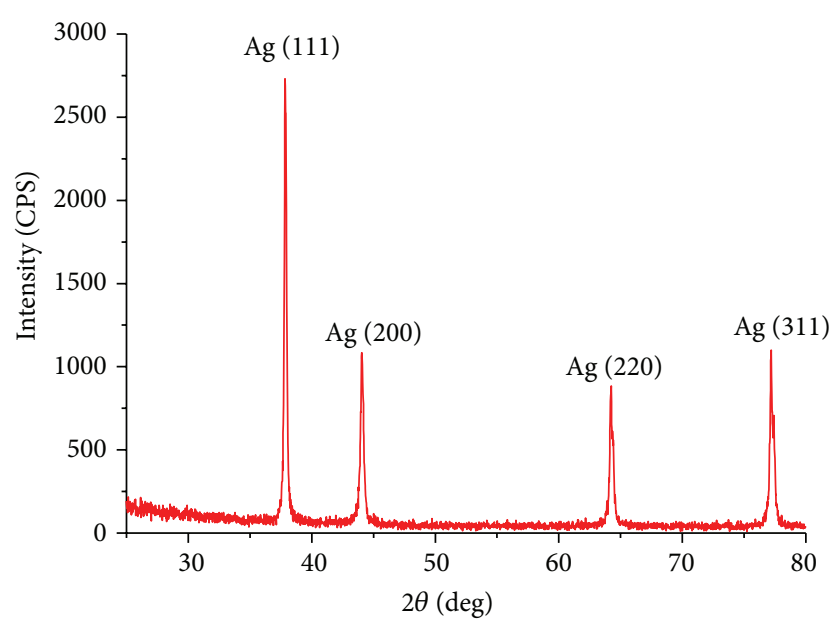

FIGURE 3: XRD pattern of porous silver powder obtained by hydrothermal precipitation at $150^{\circ} \mathrm{C}$.

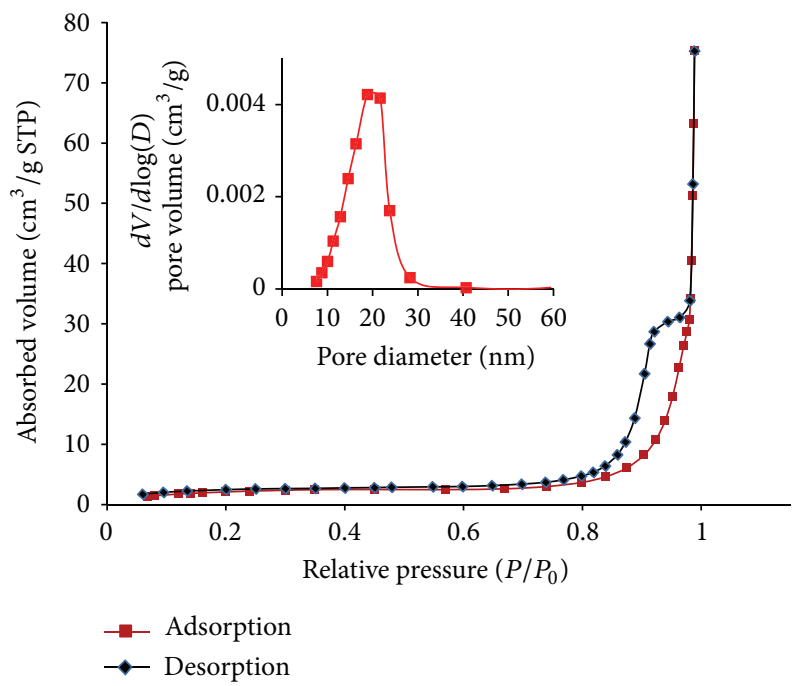

FIGURE 4: Nitrogen adsorption and desorption isotherms and pore size distribution (inset) of mesoporous silver powder.

is also in congruence with the observation of TEM and SEM images (Figures 2(c) and 2(d)).

Although hydrothermal process has been widely utilized to synthesize and grow anisotropic silver crystals, its influence on preprepared silver nanoparticles in an aqueous solution has been scarcely investigated. This short communication indicates that hydrothermal technique provide not only a good method to synthesize anisotropic silver particles but also to control the anisotropic transition of preprepared silver nanoparticles. Moreover, by increasing temperature to $150^{\circ} \mathrm{C}$, we can obtain mesoporous silver powder that could be desired for various applications.

\section{Conclusion}

This work demonstrates that hydrothermal treatment has a great effect on presynthesized silver nanoparticles. At 100 and $120^{\circ} \mathrm{C}$, silver nanoparticles undergo a transition from quasi-spherical shape to rod and plate. When temperature increases to $150^{\circ} \mathrm{C}$, they flocculate and precipitate to form mesoporous silver. The results obtained in this research suggest a new route to control the size and shape of presynthesized silver nanoparticles. This study also provides a novel method to produce a mesoporous silver powder with relative high surface area and large pore diameter from an aqueous solution of silver nanoparticles.

\section{Acknowledgment}

This study was supported by a grant from Vietnam Ministry of Science and Technology.

\section{References}

[1] October 2012, http://www.nanotechproject.org/inventories/consumer/analysis_draft/.

[2] D. Long, G. Wu, and S. Chen, "Preparation of oligochitosan stabilized silver nanoparticles by gamma irradiation," Radiation Physics and Chemistry, vol. 76, no. 7, pp. 1126-1131, 2007. 
[3] H. Wang, X. Qiao, J. Chen, and S. Ding, "Preparation of silver nanoparticles by chemical reduction method," Colloids and Surfaces A, vol. 256, no. 2-3, pp. 111-115, 2005.

[4] A. Zielińska, E. Skwarek, A. Zaleska, M. Gazda, and J. Hupka, "Preparation of silver nanoparticles with controlled particle size," Procedia Chemistry, vol. 1, no. 2, pp. 1560-1566, 2009.

[5] H. N. Chau, L. A. Bang, N. Q. Buu, T. T. N. Dung, H. T. Ha, and D. V. Quang, "Some results in manufacturing of nanosilver and investigation of its application for disinfection," Advances in Natural Sciences, vol. 9, pp. 241-248, 2008.

[6] Y.-K. Twu, Y.-W. Chen, and C.-M. Shih, "Preparation of silver nanoparticles using chitosan suspensions," Powder Technology, vol. 185, no. 3, pp. 251-257, 2008.

[7] H. Huang and X. Yang, "Synthesis of polysaccharide-stabilized gold and silver nanoparticles: a green method," Carbohydrate Research, vol. 339, no. 15, pp. 2627-2631, 2004.

[8] D. V. Quang, P. B. Sarawade, A. Hilonga et al., "Synthesis of silver nanoparticles within the pores of functionalized-free silica beads: the effect of pore size and porous structure," Materials Letters, vol. 68, pp. 350-353, 2012.

[9] D. V. Quang, P. B. Sarawade, A. Hilonga et al., "Preparation of amino functionalized silica micro beads by dry method for supporting silver nanoparticles with antibacterial properties," Colloids and Surfaces A, vol. 389, no. 1-3, pp. 118-126, 2011.

[10] D. V. Quang, J. E. Lee, J.-K. Kim, Y. N. Kim, G. N. Shao, and H. T. Kim, "A gentle method to graft thiol-functional groups onto silica gel for adsorption of silver ions and immobilization of silver nanoparticles," Powder Technology, vol. 235, pp. 221-227, 2013.

[11] D. V. Quang, P. B. Sarawade, A. Hilonga et al., "Preparation of silver nanoparticle containing silica micro beads and investigation of their antibacterial activity," Applied Surface Science, vol. 257, no. 15, pp. 6963-6970, 2011.

[12] X. Chen and H. J. Schluesener, "Nanosilver: a nanoproduct in medical application," Toxicology Letters, vol. 176, no. 1, pp. 1-12, 2008.

[13] P. K. Khanna and V. V. V. S. Subbarao, "Nanosized silver powder via reduction of silver nitrate by sodium formaldehydesulfoxylate in acidic pH medium," Materials Letters, vol. 57, no. 15, pp. 2242-2245, 2003.

[14] Z. Liu, X. Qi, and H. Wang, "Synthesis and characterization of spherical and mono-disperse micro-silver powder used for silicon solar cell electronic paste," Advanced Powder Technology, vol. 23, no. 2, pp. 250-255, 2012.

[15] J.-T. Tsai and S.-T. Lin, "Silver powder effectiveness and mechanism of silver paste on silicon solar cells," Journal of Alloys and Compounds, vol. 548, no. 105, 109 pages, 2013.

[16] G. Guo, W. Gan, F. Xiang et al., "Effect of dispersibility of silver powders in conductive paste on microstructure of screenprinted front contacts and electrical performance of crystalline silicon solar cells," Journal of Materials Science: Materials in Electronics, vol. 22, no. 5, pp. 527-530, 2011.

[17] J. C. Lin and C. Y. Wang, "Effect of surface properties of silver powder on the sintering of its thick-film conductor," Materials Chemistry and Physics, vol. 45, no. 3, pp. 253-261, 1996.

[18] W. Itoh, A. Sawada, A. Shinozaki, and Y. Inada, "New silver powders with large surface area as heat exchanger materials," Cryogenics, vol. 31, no. 6, pp. 453-455, 1991.

[19] J. K. Shon, S. S. Kong, J. M. Kim et al., "Facile synthesis of highly ordered mesoporous silver using cubic mesoporous silica template with controlled surface hydrophobicity," Chemical Communications, no. 6, pp. 650-652, 2009.
[20] J. K. Shon, J.-N. Park, S. H. Hwang et al., "Pretreatment effect on CO oxidation over highly ordered mesoporous silver catalyst," Bulletin of the Korean Chemical Society, vol. 31, no. 2, pp. 415418, 2010.

[21] H. Lu, "Fabrication and characterization of porous silver powder prepared by spray drying and calcining technology," Powder Technology, vol. 203, no. 2, pp. 176-179, 2010.

[22] K. C. Pingali, D. A. Rockstraw, and S. Deng, "Silver nanoparticles from ultrasonic spray pyrolysis of aqueous silver nitrate," Aerosol Science and Technology, vol. 39, no. 10, pp. 1010-1014, 2005.

[23] X. Shi, S. Wang, X. Duan, and Q. Zhang, "Synthesis of nano Ag powder by template and spray pyrolysis technology," Materials Chemistry and Physics, vol. 112, no. 3, pp. 1110-1113, 2008.

[24] V. Sáez and T. J. Mason, "Sonoelectrochemical synthesis of nanoparticles," Molecules, vol. 14, no. 10, pp. 4284-4299, 2009.

[25] Z. Yingjie, Q. Yitai, Z. Manwei, C. Zuyao, L. Bin, and W. Changsui, "Preparation of nanocrystalline silver powders by $\gamma$-ray radiation combined with hydrothermal treatment," Materials Letters, vol. 17, no. 5, pp. 314-318, 1993.

[26] Y. Dai, T. Deng, S. Jia, L. Jin, and F. Lu, "Preparation and characterization of fine silver powder with colloidal emulsion aphrons," Journal of Membrane Science, vol. 281, no. 1-2, pp. 685691, 2006.

[27] K. D. Kim, D. N. Han, and H. T. Kim, "Optimization of experimental conditions based on the Taguchi robust design for the formation of nano-sized silver particles by chemical reduction method," Chemical Engineering Journal, vol. 104, no. 1-3, pp. 5561, 2004.

[28] H. H. Nersisyan, J. H. Lee, H. T. Son, C. W. Won, and D. Y. Maeng, "A new and effective chemical reduction method for preparation of nanosized silver powder and colloid dispersion," Materials Research Bulletin, vol. 38, no. 6, pp. 949-956, 2003.

[29] K. Byrappa and T. Adschiri, "Hydrothermal technology for nanotechnology," Progress in Crystal Growth and Characterization of Materials, vol. 53, no. 2, pp. 117-166, 2007.

[30] M. Yoshimura and K. Byrappa, "Hydrothermal processing of materials: past, present and future," Journal of Materials Science, vol. 43, no. 7, pp. 2085-2103, 2008.

[31] Z. Wang, J. Liu, X. Chen, J. Wan, and Y. Qian, "A simple hydrothermal route to large-scale synthesis of uniform silver nanowires," Chemistry: A European Journal, vol. 11, no. 1, pp. 160-163, 2005.

[32] J. Zou, Y. Xu, B. Hou, D. Wu, and Y. Sun, "Controlled growth of silver nanoparticles in a hydrothermal process," China Particuology, vol. 5, no. 3, pp. 206-212, 2007.

[33] G. Wei, C.-W. Nan, Y. Deng, and Y.-H. Lin, "Self-organized synthesis of silver chainlike and dendritic nanostructures via a solvothermal method," Chemistry of Materials, vol. 15, no. 23, pp. 4436-4441, 2003.

[34] M. J. Rosemary and T. Pradeep, "Solvothermal synthesis of silver nanoparticles from thiolates," Journal of Colloid and Interface Science, vol. 268, no. 1, pp. 81-84, 2003.

[35] X.-L. Tang, P. Jiang, G.-L. Ge, M. Tsuji, S.-S. Xie, and Y.J. Guo, "Poly(N-vinyl-2-pyrrolidone) (PVP)-capped dendritic gold nanoparticles by a one-step hydrothermal route and their high SERS effect," Langmuir, vol. 24, no. 5, pp. 1763-1768, 2008.

[36] S. Wang and G. Shi, "Uniform silver/polypyrrole core-shell nanoparticles synthesized by hydrothermal reaction," Materials Chemistry and Physics, vol. 102, no. 2-3, pp. 255-259, 2007. 
[37] L.-B. Luo, S.-H. Yu, H.-S. Qian, and T. Zhou, "Large-scale fabrication of flexible silver/cross-linked poly(vinyl alcohol) coaxial nanocables by a facile solution approach," Journal of the American Chemical Society, vol. 127, no. 9, pp. 2822-2823, 2005.

[38] Q. Zhang, N. Li, J. Goebl, Z. Lu, and Y. Yin, "A systematic study of the synthesis of silver nanoplates: is citrate a "magic" reagent?" Journal of the American Chemical Society, vol. 133, no. 46, pp. 18931-18939, 2011.

[39] S. Lowell, J. E. Shields, M. A. Thomas, and M. Thommes, Characterization of Porous Solids and Powders: Surface Area, Pore Size and Density, Kluwer Academic Publishers, Dordrecht, The Netherlands, 2004. 

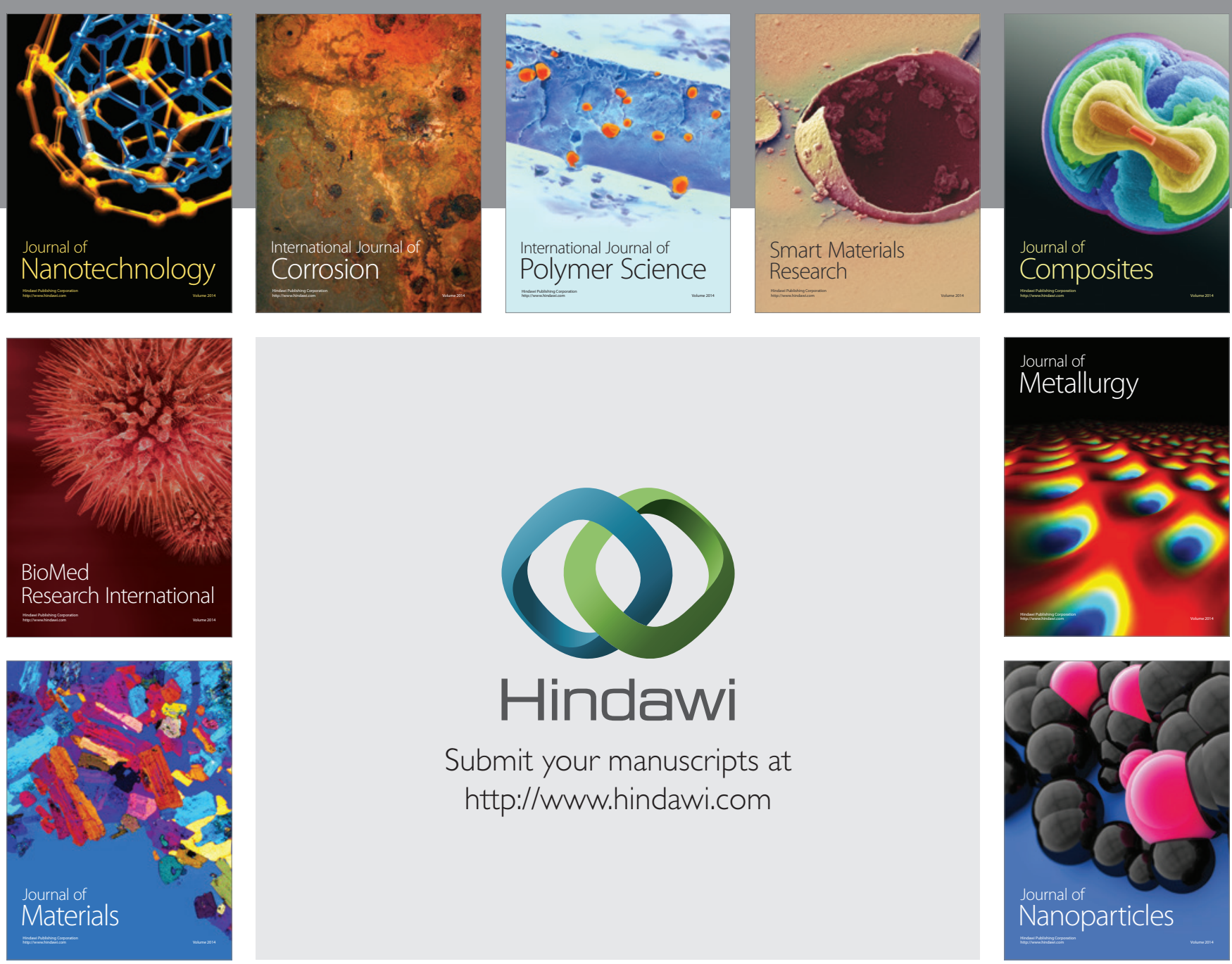

Submit your manuscripts at http://www.hindawi.com
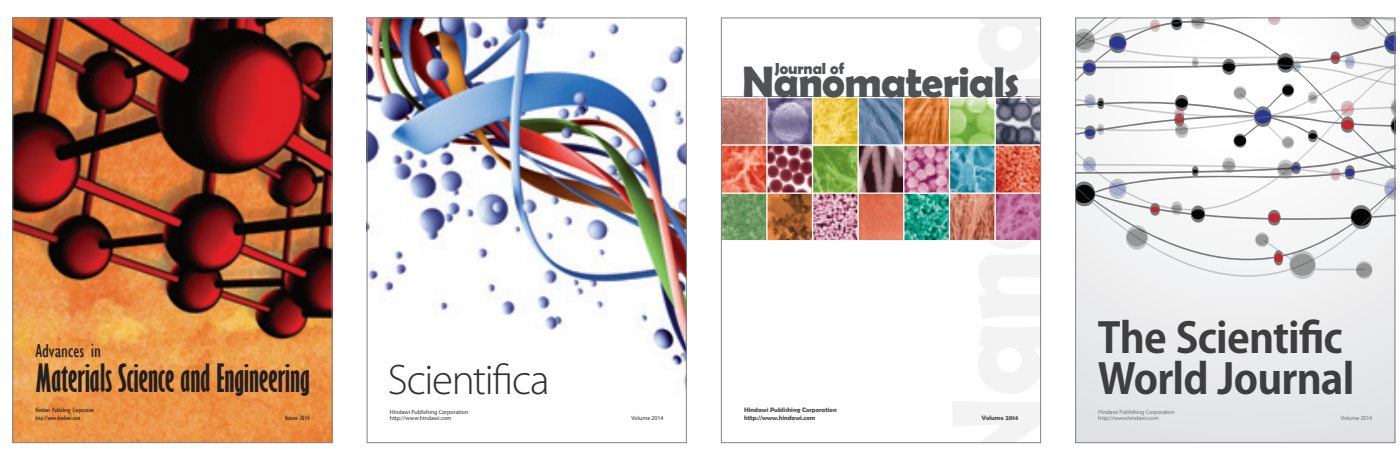

\section{The Scientific World Journal}
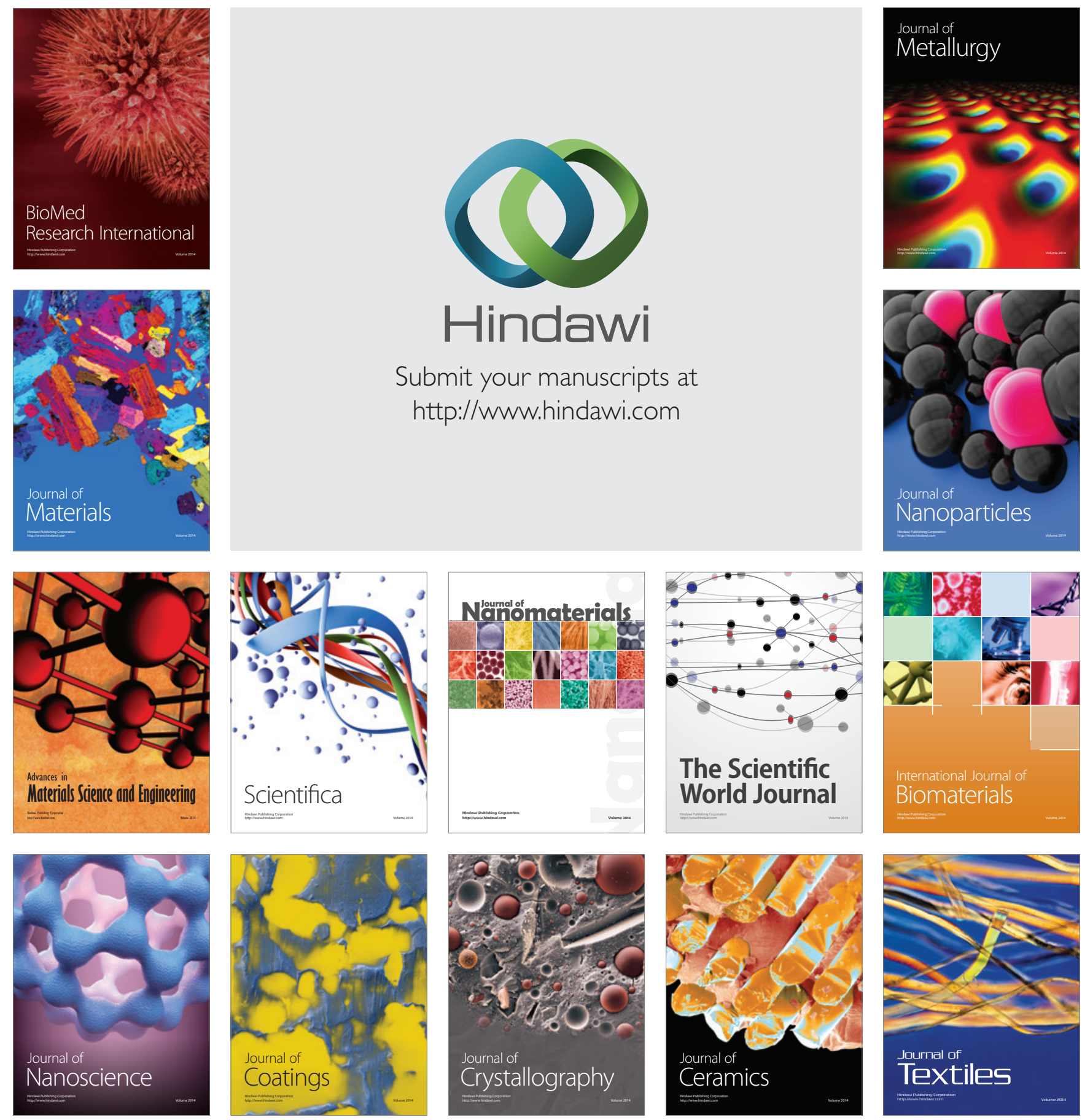